\title{
ESTUDO DE CASO: PROPOSTA DE UMA NOVA METODOLOGIA DE ORGANIZAÇÃO PARA ALMOXARIFADO.
}

\author{
DOI 10.37619/issn2447-5378.v7i1.324.50-59
}

\author{
A. A.O. Silva ${ }^{1 *} ;$ N. E. Yamada \\ 1 Faculdade de Tecnologia de São José dos Campos - Professor Jessen Vidal \\ Av. Cesare Mansueto Giulio Lattes, 1350 - Eugênio de Melo, São José dos \\ Campos/SP, CEP.: 12247-014, Brasil. \\ Telefone: (12) 3905-2423 \\ *alexaosi05@gmail.com
}

\begin{abstract}
RESUMO: Este trabalho apresenta um estudo relacionado ao almoxarifado de produtos químicos de uma empresa no ramo aeronáutico que se encontra na cidade de São José dos Campos, estes, armazenados em desacordo com as normas relacionadas ao assunto. $\mathrm{O}$ objetivo é propor a adequação deste almoxarifado às especificações de saúde e segurança no trabalho. Foi efetuada uma análise para levantamento de informações, assim, possibilitando a geração de um novo layout com as devidas identificações, organização dos produtos de acordo com seu segmento e demarcação do espaço de cada componente na área. Utilizando como ferramenta de estudo as normas regulamentas brasileiras e a metodologia $5 \mathrm{~S}$ que trata de questões voltadas especificamente para organização e padronização do ambiente. Foi proposto o novo layout adequado as normas, onde como resultado positivo tem-se um setor organizado, com controle de produtos e pessoas que utilizam o espaço, além de ser seguro para a empresa e trabalhadores.
\end{abstract}

PALAVRAS-CHAVE: Almoxarifado; 5S; normas regulamentadoras; padronização; layout; segurança

\begin{abstract}
This work presents a study related to the chemical products warehouse of a company in the aeronautical branch that is in the city of São José dos Campos, these, stored in disagreement with the norms related to the subject. The objective is to propose the adequacy of this warehouse to the specifications of health and safety at work. An analysis was carried out to gather information, thus enabling the generation of a new layout with the appropriate identifications, organization of the products according to their segment and the demarcation of the space of each component in the area. Using as a study tool the Brazilian regulatory standards and the 5S methodology that deals with issues specifically aimed at organization and standardization of the environment. Was proposed a new layout appropriate to the standards, where as a positive result there is an organized sector, with control of products and people who use the space, in addition to being safe for the company and workers.
\end{abstract}

KEYWORDS: Warehouse; 5S; regulatory norms; information; layout; security.

\section{INTRODUÇÃO.}

Após análise na empresa do ramo aeronáutico situado no município de São José dos Campos, foi observado um desvio na organização de produtos químicos, fazendo-se necessário o desenvolvimento de uma proposta de melhoria na disposição e controle dos materiais, tendo em vista sua periculosidade. 


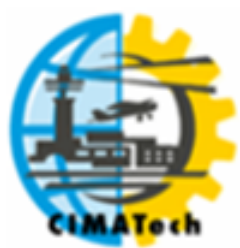

Foi constatado um problema na organização do almoxarifado de produtos químicos, tendo em vista que ele, estava com problemas na organização, limpeza, sinalização, controle e sua ficha de informação de segurança para produtos químicos era inexistente, sendo um deles a falta de controle na entrada e saída de materiais.

Atualmente, a empresa possui um almoxarifado que não se enquadra nos padrões normativos de armazenagem de produtos, no qual traz riscos à segurança dos funcionários e prejudica o trabalho na empresa.

Com base nas normas regulamentadoras $(\mathrm{NR})$ e na metodologia " $5 \mathrm{~S}$ ", será proposto um novo layout, atendendo os requisitos de segurança, criação de um modelo de controle, aplicando as sinalizações necessárias, utilização da ficha de informação de segurança para produtos químicos. Este trabalho tem como objetivo propor um novo modelo para organização do almoxarifado visando reduzir custos desnecessários a empresa, evitar desperdícios de materiais, facilitar a localização dos materiais (rastreabilidade), aplicar a armazenagem correta de cada tipo de material e identificá-los.

\subsection{OBJETIVO}

Estabelecer um método de controle de almoxarifado. Estruturar um almoxarifado já existente de acordo com as normas pertinentes a este assunto.

Para a consecução deste objetivo foram estabelecidos os objetivos específicos:

- Realizar uma investigação sobre as atuais normas, legislações, especificas de armazenagem de produtos;

- $\quad$ Propor um novo layout de armazenagem, com as adequações necessárias, produtos alocados corretamente, com as identificações necessárias.

Analisar a aplicação da metodologia " $5 \mathrm{~s}$ " com o intuito de manter as melhorias propostas.

\subsection{METODOLOGIA}

Ter como metodologia uma pesquisa estruturada aplicando uma abordagem qualitativa, exploratória, descritiva e explicativa utilizando um levantamento de dados.

\section{EMBASAMENTO TEÓRICO}

Neste capítulo serão contextualizados os assuntos que sustentam o tema escolhido, utilizando como base artigos e publicações em sites técnicos relacionados ao tema.

\subsection{ALMOXARIFADO}

Segundo Ballou (2006), o almoxarifado funciona como um "pulmão", disponibilizando produtos quando requeridos, possibilitando flexibilidade na produção e na distribuição das mercadorias.

Para um bom desempenho da realização das atividades do almoxarifado é necessária uma boa gestão da cadeia de suprimentos, que visa a integração dos diversos setores da organização. Assim, 


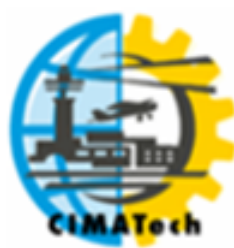

conforme Hermínio (2016), o objetivo básico na Supply Chain Management é maximizar e tornar realidade as potenciais sinergias entre as partes da cadeia produtiva, de forma a atender ao consumidor final mais eficientemente através da redução dos custos.

\subsection{LAYOUT}

Layout, segundo Slack et al (2009), é definido como o arranjo físico das estações de trabalho ou objetos em um ambiente, apresentando com clareza o fluxo do produto e posicionamento da mãode-obra, tendo a segurança como um fator limitador.

A palavra layout tem origem na língua inglesa, a terminologia é utilizada em diversas áreas profissionais. No contexto empresarial pode ser definido como arranjo físico, ou seja, a forma como são organizados máquinas, equipamentos, ferramentas, processos e mão de obra nas organizações. Em português a palavra também pode ser encontrada como leiaute, inclusive em dicionários, entretanto, no âmbito empresarial é amplamente utilizada pela expressão layout (DA ROSA; CRACO; DOS REIS; NODARI, 2014).

\subsection{METODOLOGIA 5S}

Concebido por Kaoru Ishikawa em 1950, o 5S é um método de gestão da qualidade com raízes japonesas, o qual foi desenvolvido a partir da necessidade de organizar e melhorar a produção uma vez que, neste período, pós Segunda Guerra Mundial, as fabricas se encontravam em total desorganização. Essa metodologia busca promover a disciplina na empresa através da consciência e responsabilidade de todos de forma a tornar o ambiente de trabalho agradável, seguro e produtivo (ARENA; BUGLIA; PEREIRA; TAMAE, 2011).

O método teve este nome dado por ter cinco sensos de atuação, sendo eles: Seiri, Seiton, Seiso, Seiketsu e Shitsuke. (REYES; VICINO, 2019).

Tabela 1 - 5S.

\begin{tabular}{|l|l|}
\hline SEIRI & $\begin{array}{l}\text { Eliminar o desperdício, não só os desperdícios de coisas materiais como também } \\
\text { das tarefas desnecessárias, evitando assim esforços desnecessários. } \\
\text { Representando assim o senso de utilização ou descarte. }\end{array}$ \\
\hline SEITON & $\begin{array}{l}\text { Definido pelo senso de ordenação, ou seja, consiste em definir, de forma física e } \\
\text { visual, critérios e locais apropriados para armazenamento, de ferramentas ou } \\
\text { materiais, e fluxo de informações, fazendo com que as coisas necessárias sejam } \\
\text { utilizadas com rapidez e segurança, a qualquer momento. }\end{array}$ \\
\hline SEISO & $\begin{array}{l}\text { Consiste em manter limpo o ambiente de trabalho (paredes, armários, gavetas, } \\
\text { piso etc.), a filosofia principal neste senso não consiste no ato de limpar, mas no } \\
\text { ato de não sujar. }\end{array}$ \\
\hline SEIKETSU & $\begin{array}{l}\text { Denominado senso de higiene, saúde e integridade, é alcançado com a prática dos } \\
\text { sensos anteriores. Tem vital importância para assegurar a manutenção dos 3S } \\
\text { iniciais, pois a melhoria da qualidade de vida no trabalho estimula a adesão e } \\
\text { comprometimento de todos. }\end{array}$ \\
\hline SHITSUKE & $\begin{array}{l}\text { Conceito de autodisciplina, sendo o compromisso pessoal com o cumprimento } \\
\text { dos padrões éticos, morais e técnicos, definidos pelo programa 5S. Quando as } \\
\text { pessoas passam a fazer o que tem que ser feito e da maneira como deve ser feito, } \\
\text { mesmo que ninguém veja, significa que existe disciplina. }\end{array}$ \\
\hline
\end{tabular}




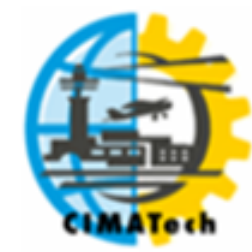

\section{Congress of Industrial \\ Management and Aeronautical \\ Technology}

ISSN 2447-5378

\subsection{SEGURANÇA NO TRABALHO}

As normas e processos adotados com a finalidade de prevenir acidentes e doenças relacionadas ao trabalho e garantir a integridade do trabalhador podem ser entendidas como Segurança no Trabalho (PEIXOTO, 2011).

Para estabelecer os parâmetros de segurança e de acondicionamento dos materiais a serem aplicados neste trabalho, foram utilizadas as normas técnicas associadas ao tema.

\subsection{NORMAS TÉCNICAS}

São os documentos estabelecidos a partir de estudos científicos, tecnológicos e experiência acumulada, visando estabelecer as regras, diretrizes ou características mínimas para obter um ótimo resultado assegurando a qualidade, segurança confiabilidade, eficiência, intercambialidade, preservação do meio ambiente, garantindo uma boa relação custo-benefício. (ABNT, 2019)

Para este trabalho serão utilizadas as seguintes normas: NBR 15524, NBR 17505-5, NR 16, NR 23, NR 20, NBR 5413, NBR 14725. Abaixo um breve resumo referente as NR e NBR

\subsubsection{NR 16 - ATIVIDADES E OPERAÇÕES PERIGOSAS}

Segundo Brasil (2019), esta NR apresenta as obrigações do empregador para com o empregado e as regras a serem seguidas para o armazenamento de produtos perigosos.

Define também que produtos inflamáveis líquidos e gasosos liquefeitos devem ser armazenados em tanques ou vasilhames, com arrumação de vasilhames ou quaisquer outras atividades sendo executadas dentro do prédio de armazenamento de inflamáveis ou em recintos abertos, e com vasilhames cheios de inflamáveis ou vazios não desgaseificados ou decantados. (BRASIL, 2019)

\subsubsection{NR 20 - SEGURANÇA E SAÚDE NO TRABALHO COM INFLAMÁVEIS E COMBUSTÍVEIS}

A norma regulamentadora 20 apresenta requisitos para gestão das atividades exercidas com extração, produção, armazenamento, transferência, manuseio e manipulação de inflamáveis e líquidos combustíveis contra o risco de acidentes nessas situações.

Ela mostra como devem ser executadas as atividades desde a concepção do projeto de um armazém de produtos inflamáveis e combustíveis, determinando cada classe de produtos, até o manuseio desses produtos pelos trabalhadores, seus treinamentos e gestão desse tipo de ambiente.

As instalações, devem ter um projeto elaborado levando em consideração aspectos de segurança, saúde ocupacional dos trabalhadores envolvidos e meio ambiente, mantendo sempre os padrões exigidos no que se refere a distanciamento de outras instalações, fontes de ignição, edificações, máquinas, áreas de movimentação e áreas circunvizinhas, incluindo mecanismos corta-fogo e de contenção.

\subsubsection{NR 23 - PROTEÇÃO CONTRA INCÊNDIOS}

A NR 23 visa estabelecer as medidas para prevenção contra incêndio, informando que todos os locais de trabalho deverão possuir algum tipo de proteção contra incêndio, saídas suficientes para rápida evacuação do prédio, em caso de incêndio, equipamentos suficientes para extinguir o fogo ainda em seu início e pessoas treinadas para usar estes equipamentos. (BRASIL, 2019) 


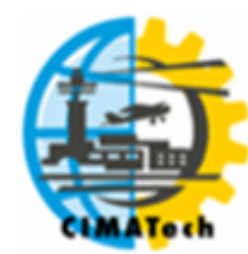

\section{Congress of Industrial \\ Management and Aeronautical}

\subsubsection{NBR 17505 - ARMAZENAMENTO DE LÍQUIDOS INFLAMÁVEIS E COMBUSTÍVEIS}

Esta parte da ABNT NBR17505 aplica-se a operações que envolvam o uso ou o manuseio de líquidos inflamáveis e combustíveis, tanto como atividade principal como eventual, exceto quando cobertas por outra parte especifica desta parte da ABNT NBR17505.

\subsubsection{NBR 15524-2 - SISTEMAS DE ARMAZENAGEM}

A seguir será explicado o tópico de armazenagem.

\subsubsection{ARMAZENAGEM DE PRODUTOS}

Produtos químicos não podem ser armazenados de qualquer forma, como classificados por ordem alfabética ou numérica. Eles devem receber um olhar diferenciado. Confira como fazer o passo a passo.

\subsubsection{SEGREGAÇÃO}

Inicialmente, é importante segregá-los e guardá-los com base em suas compatibilidades: incêndio, explosão e formação de gases tóxicos são implicações indesejáveis quando opostos colidem.

\subsubsection{3 ÁREAS DE CIRCULAÇÃO}

O próximo passo é manter áreas de circulação e passagem de laboratórios livres para que haja a circulação de ar, não usar escada para o armazenamento desses materiais, fazer com que reagentes químicos e equipamentos sejam devidamente estocados, limpar de forma rápida e segura todo e qualquer reagente derramado, além de manter fora do espaço dos laboratórios reagentes sem etiquetas.

\subsubsection{SINALIZAÇÃO}

A sinalização é uma das principais medidas a serem tomadas. Havendo risco biológico, os acessos aos laboratórios devem estar identificados com o emblema internacional. Além disso, é preciso limitar o acesso e manter o controle da entrada de pessoas, apenas quem tem vínculo com a atividade pode acessar o local.

O cumprimento das normas da ABNT para armazenagem é de extrema importância para as empresas, pois garante a qualidade dos produtos em um padrão internacional, disciplina os processos, aumenta a produtividade e a segurança.

\subsubsection{NBR 14725 - PRODUTOS QUÍMICOS - INFORMAÇÕES SOBRE SEGURANÇA, SAÚDE E MEIO AMBIENTE}

A NBR 14725 trata-se de produtos químicos (informações sobre segurança, saúde e meio ambiente). Ela está separada em 4 partes, sendo elas: Parte 1: Terminologia; Parte 2: Sistema de classificação de perigo; Parte 3: Rotulagem; Parte 4: Ficha de informações de segurança de produtos químicos (FISPQ). 


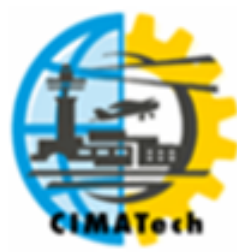

A parte 2 trata-se do sistema de classificação de perigo estabelece critérios para o sistema de classificação de perigos de produtos químicos, sejam eles substâncias ou misturas, de modo a fornecer ao usuário informações relativas à segurança, à saúde humana e ao meio ambiente. Ela se aplica a todos os produtos químicos (substâncias químicas puras e suas misturas).

\subsection{ISHIKAWA}

Diagrama de Ishikawa ou Espinha de Peixe, tem como objetivo encontrar a causa-raiz de um problema, tem como ponto de partida o processo, desde seu início até o final, analisando os fatores: Máquina, Método, Mão de obra, Matéria-prima, Meio ambiente e Medida. (HERMOGENES; SANTOS; WALKER, 2019)

\section{DESENVOLVIMENTO DA TEMÁTICA}

Tendo em vista a desorganização da área de armazenamento químico na empresa e a falta de controle de acesso, compras e utilização de materiais verificou-se a necessidade de organização e melhor gerenciamento das atividades nesse setor.

No almoxarifado em estudo são encontrados produtos químicos, sendo em sua maioria tintas, solventes e outros produtos inflamáveis, todos juntos, sem padronização e o armazenamento em desacordo as normas de segurança, sendo elas NRs e NBRs citadas anteriormente no Capítulo 2.

A parte de identificação e especificações de cada produto é definida pela NBR 14752, determinando quais materiais são reagentes e se podem estar perto de outros.

\subsection{ARMAZENAGEM DE PRODUTOS INFLAMÁVEIS}

A NR 16 define as operações no almoxarifado em estudo como atividades perigosas, devido a capacidade estar acima dos 200 litros de líquidos inflamáveis estabelecidos na norma. Sendo necessário a demarcação de um círculo de 7,5 metros, com o produto no centro, para este trabalho será demarcada uma área proporcional ao tamanho do almoxarifado.

As instalações consideram primordialmente os aspectos de segurança, saúde ocupacional e meio ambiente, seguindo os padrões de distanciamento de outras instalações, fontes de ignição, edificações, máquinas, áreas de movimentação e áreas circunvizinhas, incluindo mecanismos cortafogo e de contenção, estabelecidos na NR 20.

A NBR 15524-2 define que produtos com bases químicas diferentes devem ser acondicionados segregados.

Para enquadrar o layout de acordo com a NR 20, foi feito um estudo para segregar os tipos de produto em comum em um lugar definido e identificado. A ideia é que após a definição dos locais de armazenamento, os envolvidos sejam treinados e capacitados para a manutenção da organização e atuação nas atividades.

O local de armazenamento deve ser ventilado, afastado de superfícies quentes e faíscas, as instalações elétricas devem ser à prova de explosão, evitando o acúmulo de cargas eletrostáticas, e devesse utilizar EPIs para a movimentação e armazenamento dos materiais, estabelece a NBR 14725.

A disposição dos armários obedece a NBR 17505, especifica que no local onde há produtos inflamáveis não poderão estar instalados mais do que três armários ou gabinetes. 


\subsection{SINALIZAÇÃO E IDENTIFICAÇÃO}

A NR 23 estabelece que em áreas em que haja risco de incêndio é necessário a sinalização luminosa indicando a saída e instalação de extintores na área.

NBR 15524-2 estabelece que é necessário limitar e manter o acesso de pessoas para apenas a aquelas que tem atividades vinculadas a área, também sinalizar com cores as áreas onde estão os equipamentos de segurança, áreas de risco e as canalizações utilizadas para líquidos e gases, além dos sinais convencionais ou palavras. Para o caso dos produtos que oferecem risco biológico, serão identificados com emblema internacional.

Para identificação dos produtos, será utilizado sua FISPQ, contendo: identificação do produto e da empresa, identificação de perigos, composição e informações sobre os ingredientes, medidas de primeiros-socorros, medidas de combate a incêndio, medidas de controle para derramamento ou vazamento, manuseio e armazenamento, controle de exposição e proteção individual, propriedades físicas e químicas, estabilidade e reatividade, informações toxicológicas, informações ecológicas, considerações sobre tratamento e disposição, informações sobre transporte, regulamentações e outras informações.

\subsection{CONTROLE DO FLUXO DE MATERIAIS NO ALMOXARIFADO}

Para controle dos materiais, fica estabelecido que o setor de compras será o responsável pela administração de entradas e saídas de materiais, relacionadas ao almoxarifado, com a utilização do padrão FEFO (First Expired First Out) para produtos perecíveis, zelar pelo seguimento das regras de armazenagem, como $5 \mathrm{~S}$ e as normas regulamentadoras para cada tipo de material, e garantir a disponibilidade do material.

\subsection{DIAGRAMA DE ISHIKAWA}

Para ter o entendimento dos obstáculos que impedem o atingimento do objetivo, foi elaborado um Diagrama de Ishikawa, conforme Figura 1.

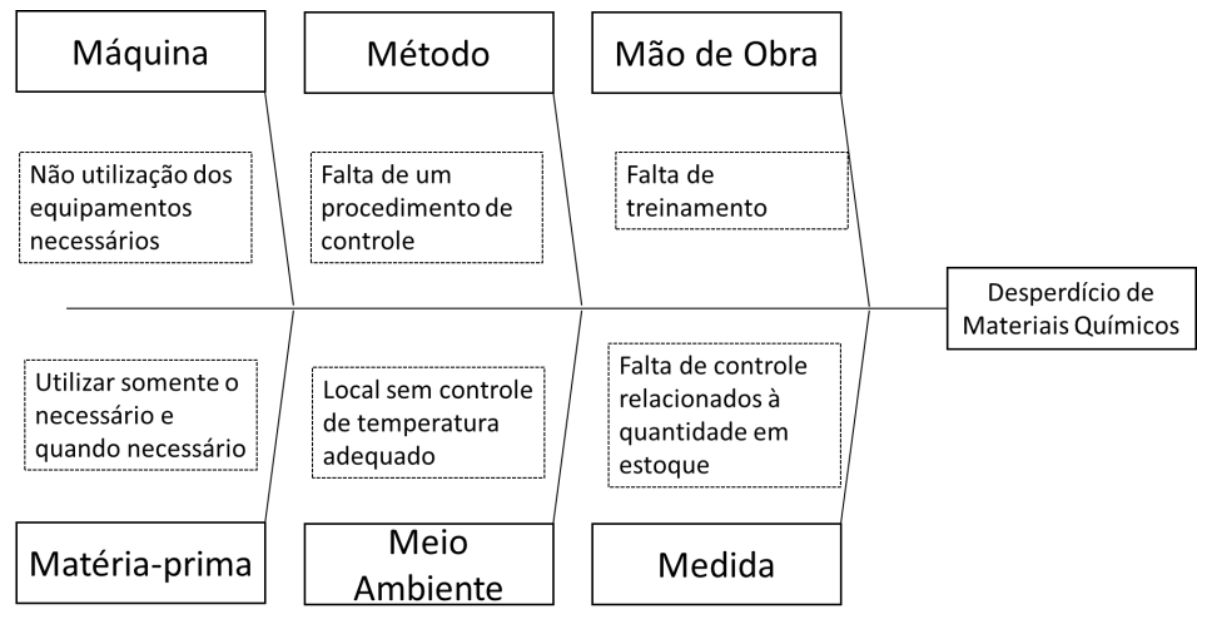

Figura 1 - Diagrama de Ishikawa.

Fonte: autores 


\section{RESULTADOS E DISCUSSÃO}

Com o novo layout, fica evidente os resultados obtidos com a nova organização do almoxarifado e padronização de armazenagem, garantindo a empresa maior segurança em suas operações realizadas naquela área. A Figura 2 apresenta o desenho isométrico do layout, possibilitando uma visão geral do almoxarifado, ficando possível uma posterior comparação entre a situação do almoxarifado atualmente e a proposta de melhoria.

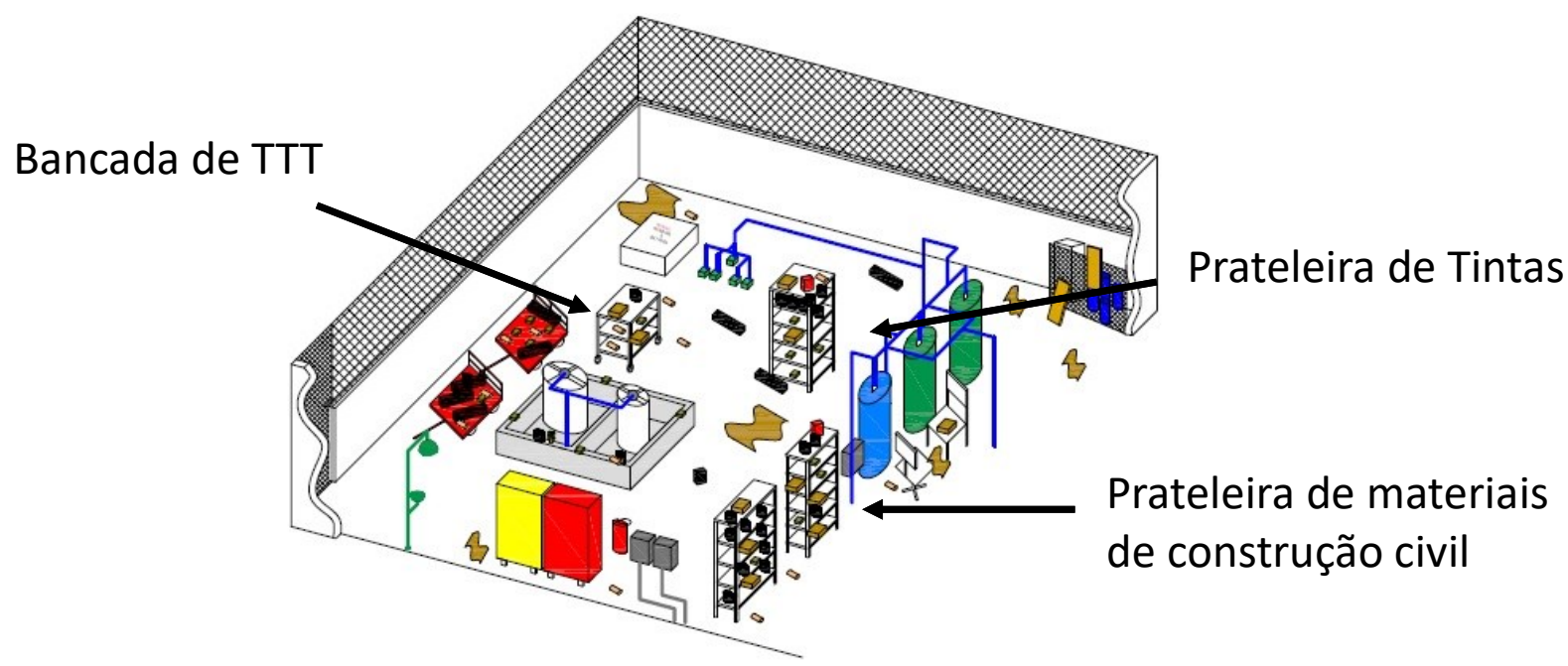

Figura 2 - Layout Atual do Almoxarifado.

Fonte: Autores.

Na Figura 2 são apresentados os produtos abaixo:

Tabela 2 - Produtos presentes no layout atual.

\begin{tabular}{|l|}
\hline \multicolumn{1}{|c|}{ ALMOXARIFADO ATUAL } \\
\hline Álcool \\
\hline Diesel \\
\hline Removedores \\
\hline Gasolina \\
\hline Materiais de construção \\
\hline Dry wall \\
\hline Tintas envelhecidas \\
\hline Entulho \\
\hline Tanques de Água Ionizados \\
\hline
\end{tabular}

A Figura 3 apresenta a proposta de melhoria para o almoxarifado, aplicando os padrões estabelecidos nas normas, apresentadas nos capítulos 2 e 3. 


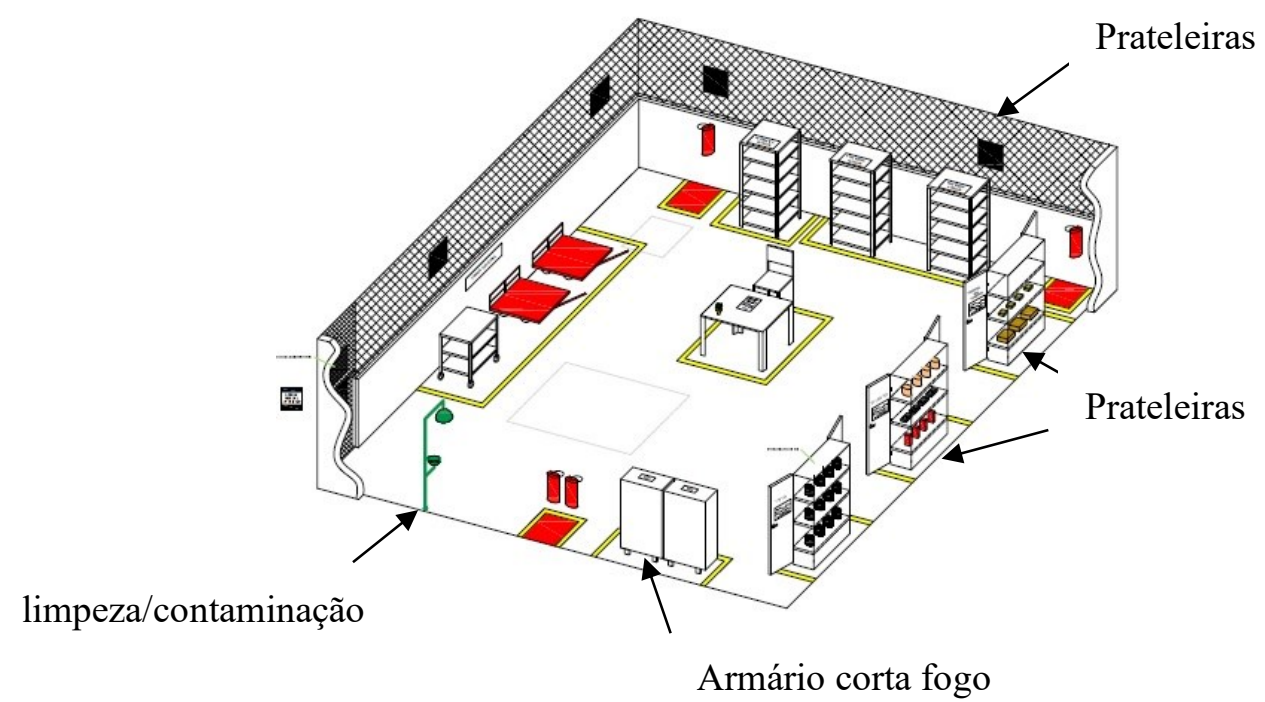

Figura 3 - Proposta do Novo Layout.

Fonte: Autores.

Com a utilização do layout proposto na Figura 3, a organização seria para os produtos abaixo:

Tabela 3 - Produtos para o layout proposto.

\begin{tabular}{|l|}
\hline \multicolumn{1}{|c|}{ ALMOXARIFADO NOVO } \\
\hline Lixas \\
\hline Álcool Isopropílico \\
\hline Selante B2 \\
\hline Selante C2 \\
\hline Primer \\
\hline Removedor \\
\hline Tinta \\
\hline Luvas (P M G GG) \\
\hline
\end{tabular}

Os materiais que não foram usados e não tinham utilidades foram descartados os que apresentavam condições de uso foram usados no próprio projeto como as prateleiras.

\section{CONSIDERAÇÕES FINAIS}

Problemas de organização, padronização e controle em depósitos são comuns em empresas, ocasionando elevação nos custos das operações, perdas de materiais e acidentes, fatores que com o passar do tempo desperdiçam capital e recursos.

Para este trabalho, o layout atual apresenta fatores necessários para o desperdício de capital, como: a falta de controle, possibilitando a retirada ou entrada de materiais sem ser feito um acompanhamento, ocasionando compras desnecessárias; falta de padronização na armazenagem dos materiais químicos, nos quais armazenados incorretamente podem gerar problemas para os 


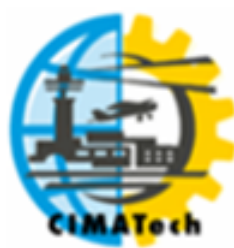

\section{Congress of Industrial

trabalhadores e empresa, como incêndios, por se tratar de produtos inflamáveis; desorganização, onde dificulta a localização dos materiais e regras de segurança.

Devido à falta de controle, não foi possível quantificar o valor ou o que foi realmente desperdiçado, porém com o novo layout, as melhorias necessárias apresentadas para adequar o almoxarifado nas normas e garantir a segurança dos trabalhadores, com a implementação da metodologia $5 \mathrm{~S}$, os problemas com organização, padronização e controle podem solucionados e evitálos. Com o novo modelo de controle perdas podem ser evitadas.

Analisando a proposta, o trabalho apresenta soluções para os problemas encontrados pelo Diagrama de Ishikawa, com isso acredita-se que a implementação trará o benefício esperado, controle do que entra e saí do almoxarifado.

\section{REFERÊNCIAS}

ABNT. Definição. Disponível em: http://www.abnt.org.br/normalizacao/o-que-e/o-que-e. Acesso em: 01 de maio de 2019.

ARENA, K. O.; BUGLIA, P. R.; PEREIRA, M. F. P.; TAMAE, R. Y. Método 5S: uma abordagem introdutória. Revista Científica Eletrônica de Administração, ano, v. 11, p. 1-11, 2011.

BALLOU, R. H. Gerenciamento da Cadeia de Suprimentos-: Logística Empresarial. $5^{\text {a }}$ Ed. - Porto Alegre: Bookman Editora, 2006.

BRASIL. NR 16 - Atividades e Operações Perigosas. Disponível em: http://www.trtsp.jus.br/geral/tribunal2/LEGIS/CLT/NRs/NR_16.html. Acesso em: 07 de maio de 2019.

BRASIL. NR $23-$ Proteção Contra Incêndios. Disponível em: http://www.guiatrabalhista.com.br/guia/nr23.htm. Acesso em: 07 de maio de 2019.

DA ROSA, G. P., CRACO, T., DOS REIS, Z. C., \& NODARI, C. H. A reorganização do layout como estratégia de otimização da produção. Revista Gestão da Produção Operações e Sistemas, v. 9, n. 2, p. 139, 2014.

HERMINIO, D. F. Proposta de estruturação de almoxarifado de produtos químicos do IPEFARMUFPB. 2016.

HERMOGENES, L. R. S.; SANTOS, M.; WALKER, R. A. Utilização do Diagrama de Ishikawa como ferramenta de análise da causa raiz do alto índice de perdas em uma Indústria de plásticos no Rio de Janeiro. In: SIMPÓSIO DE PESQUISA OPERACIONAL E LOGÍSTICA DA MARINHA, 19., 2019, Rio de Janeiro, RJ. Anais [...]. Rio de Janeiro: Centro de Análises de Sistemas Navais, 2019.

PEIXOTO, N. H. Segurança no Trabalho. $3^{\mathrm{a}}$ ed. - Santa Maria: UFSM, CTISM, Sistema Escola Técnica Aberta do Brasil, 2011.

REYES, A. E. L.; VICINO, S. R. Programa 5S. Disponível em: http://www.esalq.usp.br/qualidade/cinco_s/pag1_5s.htm. Acesso em: 16 de abril de 2019.

SLACK, N., CHAMBERS, S., \& Johnston, R. Administração da produção. São Paulo: Atlas, 2009. 